\title{
LETTER FROM THE DIRECTOR
}

Policy Perspectives, the Trachtenberg School of Public Policy \& Public Administration's superb student journal is celebrating its silver anniversary with this volume. That is 25 years of embodying our school's motto of "doing good and doing it well" by producing a journal of research related to public policy and public administration that is timely and significant.

Articles in this issue demonstrate the ways public policy can be broad and the ways it can be personal. Tinsae Gebriel (MPP '18) examines the question "Is Drug Testing Temporary Assistance for Needy Families Applicants a Good Use of Government Funds?” providing a broad look at economic efficacy of the law for the state of Arkansas. Lauryn King (MPP '18) demonstrates how a public policy decision can have very personal implications with "Labor in Chains: The Shackling of Pregnant Inmates."

The research included in this volume addresses issues close to home and far afield. Laura Erickson (MPP'18) utilized behavioral economics to explore reducing recidivism through connectional education while Matthew Dotzler (MPP '18) researched the U.S. and the Turkish-Kurdish conflict.

From Amanda (Swanson) Goff's (MPP '18) behavioral economics examination of the GI Bill and its incentivization of higher education to Francisca Alba's (MPP '19) economic analysis of the nonparticipation problem regarding social benefits programs, each article demonstrates the dedication of our entire community - faculty, students and alumni - to advance effective governance through public service education.

Each of these articles benefited from student editors and faculty reviewers, and from the authors' willingness to research, write, revise, research more and then revise again.

This volume also includes four interviews with Trachtenberg School alumni working in various capacities and subsectors of the public policy and public administration field as well as three of the outstanding blog posts that first appeared on www.policy-perspectives.org, the blog associated with the Policy Perspectives student media.

If you haven't yet listened to the GW Wonkcast, the student-run podcast produced as part of Policy Perspectives, I hope you'll download an episode from iTunes or your favorite podcast source. We couldn't really highlight the podcast team's outstanding work in the journal, but hope you'll give it a listen.

Between the articles, blog posts and podcasts, the research of our students is available for public administrators and fellow researchers in the field. We hope you enjoy this print copy of the journal and seek out the articles from this issue and past issues on Google Scholar as well as the www.policy-perspectives.org website.

\section{Kathryn Newcomer, PhD}

Director

The Trachtenberg School of Public Policy and Public Administration 